\title{
$\$$ Research Square

\section{Effect of Graphene additives on the structure and the optical parameters of the pure sodium borate glass}

Hosam Mohamed Gomaa ( $\sim$ H_goumaa@yahoo.com )

Pharaohs-Higher Institute for Computer, Information Systems and Management, Giza, Egypt https://orcid.org/0000-0002-4806-7867

H. A. Saudi

Al-Azhar University, (Girls' Branch)

I.S. Yahia

King Khalid University

H.Y. Zahran

Ain Shams University

\section{Research Article}

Keywords: Graphene, Glass, Density, Hardness, Optical, Optoelectronic

Posted Date: October 26th, 2021

DOI: https://doi.org/10.21203/rs.3.rs-1010008/v1

License: (a) (i) This work is licensed under a Creative Commons Attribution 4.0 International License. Read Full License

Version of Record: A version of this preprint was published at Journal of Electronic Materials on February 20th, 2022. See the published version at https://doi.org/10.1007/s11664-022-09478-x. 


\section{Effect of Graphene additives on the structure and the optical parameters of the pure sodium borate glass}

Hosam M. Gomaa ${ }^{(1)^{*}}$, H. A. Saudi ${ }^{(2)}$, I.S. Yahia ${ }^{(34,5)},(6,7)$, H.Y. Zahran

\section{Abstract:}

This work has been performed to knowledge the effect of insertion of pure graphene which is an organic two-dimensional material throughout the structural matrix of the pure sodium borate glass according to the chemical formula; 1 mol. $\left[\mathrm{Na}_{2} \mathrm{~B}_{4} \mathrm{O}_{7} .10 \mathrm{H}_{2} \mathrm{O}\right]+\mathrm{x} g$ Graphene, where $0 \leq \mathrm{x} \leq 3 \mathrm{~g}$. A set of four solid samples have been prepared using the fast cooling method from their melts at $1000 \pm 20^{\circ} \mathrm{C}$. The prepared solids have been characterized using the XRD technique, which indicates the amorphous nature of all four samples, as well as showing an increase in the count rate as the content of graphene increases. FTIR spectral analysis clarified that the increase in the graphene content caused an increase in $\mathrm{BO}_{4}$ concentration with respect to $\mathrm{BO}_{3}$, as well as an amount of graphene that has been oxidized was shared as glass network formers. The measured values of both bulk density and the microhardness showed a slight increase as the graphene content increased. Optical measurement showed an increase in the optical absorbance, direct bandgap, indirect bandgap, and optical bandage. Also, the values of optoelectronic parameters increased when the graphene content increased, to be larger than that of the pure $\mathrm{ZnO}$, and $\mathrm{CO}-\mathrm{ZnO}$ which make the studied glass to be good candidates for nonlinear optical applications. Both the metallization factor and Urbach's energy showed that the crystallinity degree increased when the content of graphene increased.

Keywords; Graphene, Glass, Density, Hardness, Optical, Optoelectronic

Corresponding Author; Hosam M Gomaa, (프goumaa@yahoo.com) 


\section{Introduction:}

Graphene is an amazing two-dimensional (one layer) substance, its high electronic mobility gives it unique electronic properties as well as considerable mechanical resistance [1,2]. Also, graphene possesses a high surface area and high value of Young's modulus, which nominates it for a large number of different applications like energy storage, energy conversion, and electronic sensors [1, 2]. Graphene shows a disadvantaged behavior where it has no bandgap in its perfect form, however, such defect is used to alter its other properties. Graphene defect is not stationary so its modification impacts the other properties. The modification mechanism could be physically by irradiation and/or chemically by dopants which can modify the graphene electronic structure [25]. The chemical modulation could be doped graphene by another substance like nitrogen in graphene or add graphene to another substance like boron [2, 6]. Accordingly, it was proposed to inoculate the oxide glass with pure graphene and check the different properties to estimate how the graphene impurities impact the different properties of oxide glass. Among all types of oxide glass pure sodium borate glass has been chosen because of its own properties which make it the most used glass. Sodium borate glass is a transparent glass of a low melting point, low glass transition point, high electric resistance, etc. The more interesting and distinct character of the borate glass and for which it was chosen is its two-building groups $\mathrm{BO}_{3}$ and $\mathrm{BO}_{4}$. The ratio $\mathrm{BO}_{3}: \mathrm{BO}_{4}$ is a guide tool related to the changes in the structural and physical properties of the borate glass [7-15]. The more interesting and distinct character of the borate glass and for which it was chosen is its two-building groups $\mathrm{BO}_{3}$ and $\mathrm{BO}_{4}$. Where the ratio $\mathrm{BO}_{3}: \mathrm{BO}^{4}$ is a guide tool related to the changes in the structural and physical properties of the borate glass [7-15]. Finally, this study is to estimate the impact of graphene impurities on the structural, physical, and optical properties of the pure sodium borate glass.

\section{Experimental techniques \$ methods:}

1mol. $\left[\mathrm{Na}_{2} \mathrm{~B}_{4} \mathrm{O}_{7} \cdot 10 \mathrm{H}_{2} \mathrm{O}\right]+\mathrm{x}$ g Graphene, where $\mathrm{x}=0,1,2$, and 3

This chemical formula has been used to prepare a set of four solid samples, where the preparation process was carried out using the rapid cooling technique of the glass mixtures, from the Melting temperature $1000 \pm 20^{\circ} \mathrm{C}$ to room temperature $37^{\circ} \mathrm{C}$. the preparation mechanism consisted of calculating one mole of cupric sodium borate glass, and then adding graphene with masses according to the previous chemical formula, where the resulted samples have been named as S1, 
$\mathrm{S} 2, \mathrm{~S} 3, \mathrm{~S} 4$. Some solid blocks were taken from the prepared samples and polished to be of the same thickness for density and optical measurements, while the remaining portions were milled/grounded for XRD and FTIR measurements. The bulk densities of the samples were measured using the Archimedes buoyancy method, the optical measurements ware obtained using Cary 5000 Varian Double Beam UV-vis-NIR Spectrometer, of resolution $2 \mathrm{~nm}$, while ThermosFTIR 200 spectrophotometer was used to obtain the Infrared transmission spectra of all investigated glasses, at room temperature, in the frequency range $400-4000 \mathrm{~cm}^{-1}$. SX-60 PA JEOL diffractometer (JAPAN) equipped with Ni-filtered $\mathrm{CuK} \alpha$ radiation $(\lambda=1.5416 \AA)$ was used to obtain the X-ray powder diffraction patterns.

\section{Results Discussion:}

\section{XRD: Identification of prepared solids;}

Figure 1a depicts the X-ray diffraction patterns for the four prepared samples that exhibited the same character, where no sharp peaks but only two broad humps have been observed. this result confirms the amorphous natures of the prepared samples, so they can be referred to as glass samples. For the more intensive study, the measured XRD data were normalized to cancel the measurement defects, as well as for correct comparison between samples. The normalization process resulted in all samples are matched to each other by the form shown in Figure 1b for sample $S 2$, as a representative figure. As shown in figure $1 \mathrm{~b}$, the normalized spectra were deconvoluted into two different broad peaks, the relative intensity of the left-side peak is approximately twice that of the right-side one, while the relative area of the right-side peak is two thirds that of the left-side one. Depending on the mechanism of how the XRD powder technique work, the left-hand-side, and right-hand-side peaks are referred to as $K \alpha 1$ and $K \alpha 2$, respectively, which may indicate two superimposed structural phases differ in the interatomic spacing [16-17]. Such a result may be acceptable for the prepared glasses that contain only one glass network former $\mathrm{B}_{2} \mathrm{O}_{3}$ as well as one glass network modifier $\mathrm{Na}_{2} \mathrm{O}$. Accordingly, the two observed phases maybe represented the two main groups of the borate glass $\mathrm{BO}_{3}$, and $\mathrm{BO}_{4}$. Figure 1c shows the measured XRD patterns for the graphene-free sample S1, graphene-doped samples (S2, S3, and S4), and the pure Graphene-powder S0, for comparison. According to figure 1c, it can be imagined that the majority of the graphene-additives didn't share in the construction of the glass network, but only occupied the interstitial vacancies, which may explain the increase in the value of the absolute intensity (counting rate) of XRD when the graphene content increased. Such action causes a 
decrease in the density of the free spaces throughout the glass matrix, which in turn act to increase the glass density. The measured density, table (1), confirmed this expectation, where the value of the measured density increased when the graphene content increased.

\section{FTIR: drafting the internal structure;}

Figure 2a illustrates the normalized FTIR spectra of both the graphene-free sample and graphenedoped samples. All the graphs are similar in shape but differ in the peaks intensity and broadness, which increased when the graphene content increased. Figures $2 \mathrm{~b}$ and $2 \mathrm{c}$ show the deconvoluted FTIR spectra for graphene-free, S1, and graphene-rich samples, S4, respectively. According to the previous studies [18-28], the absorption bands due to borax' groups' vibration have been observed at 710, 13530, and $1550 \mathrm{~cm}^{-1}$ for $\mathrm{BO}_{3}$ groups, as well as $820-1060 \mathrm{~cm}^{-1}$ for $\mathrm{BO}_{4}$ groups. As seen in figures $2 \mathrm{~b}$ and $2 \mathrm{c}$, the graphene additives caused an increase in $\mathrm{BO}_{4}$ concentration and a decrease in $\mathrm{BO}_{3}$. However, $\mathrm{BO}_{3}$ is still the dominant structure which consequently means existence of a large number of the non-bridging oxygens. While the increase in $\mathrm{BO}_{4}$ concentration may explain the appeared peak at $1730 \mathrm{~cm}^{-1}$ for all graphene-doped samples due to the vibration of $\mathrm{C}=\mathrm{O}$, terminal oxygens [29]. Such peak has low intensity as well as a small creative area, which means that a small amount of graphene has been oxidized by the oxygen atoms that are linked to the boron cations. in other words, a little amount of graphene content share in the glass network as a glass former, after it was oxidizing by the oxygen atoms. Since the bond energy of $-\mathrm{C}=\mathrm{O}(741 \mathrm{~kJ} / \mathrm{mol})$ is larger than B-O $(536 \mathrm{~kJ} / \mathrm{mol})$, it can be expected an increase in the values of both density and hardness. By reviewing table (1), the measured density and hardness are in agreement with the last expectation, which is a confirmation of the results that have been obtained by different tools.

\section{Optical \& Optoelectronic parameters;}

Figure 3 illustrates the variation of both the optical transmittance and absorbance with the content of graphene. It's clear that at constant photon energy, the absorbance increased while the transmittance decreased when the content of graphene was increased. since all samples have been adjusted to have the same thickness, the increase of absorbance value can be assigned to more than one factor, such as the density value increase, the abundance of the nonbridging oxygens, as well as the formation of $\mathrm{C}=\mathrm{O}$ bonds where the electronic $n-\pi^{*}$ transitions can take place [29]. To determine the values of the direct and indirect optical transitions energy gaps Tauc's relation (r1) 
has been used, where the absorption coefficient $\alpha$ has been calculated using relation (2) by the values of absorbance A of the sample and its thickness t [30-34].

$(\alpha E)^{\gamma} \sim\left(E-E_{g}\right)$, Where $\quad E_{g}=\left\{\begin{array}{c}E_{d} \text { when } \gamma=2 \\ E_{\text {in }} \text { when } \gamma=1 / 2\end{array}\right.$

$\alpha=2.303 A t^{-1}$,

As shown in figures $4 \mathrm{a}$ and $4 \mathrm{~b}$, there is a blue shift in the intersection of the straight sections, resulted from plots $(\alpha \mathrm{E})^{2}$ and $(\alpha \mathrm{E})^{0.5}$ versus $\mathrm{E}$, with the $\mathrm{x}$-axis (Photon energy). Such a result indicates an increase in the optical bandgaps when the content of graphene increases, which may affect the other optoelectronic parameters like the linear and nonlinear refractive indices, $n, n_{2}$, as well as the linear and nonlinear optical susceptibilities, $\chi^{(1)}, \chi^{(3)}$, as well as the metallization factor M. The obtained values for both direct and indirect energy gaps have been recorded in table (1). To estimate the exact bandage $\mathrm{E}_{\mathrm{m}}$ which is required to obtain the mention optoelectronic parameters, the values of the direct bandgap $\mathrm{E}$ direct have been used to fit the measured absorption coefficient by the hydrogenic excitonic model (HEM) [35]. This model was suggested by Elliott et al. [35-36] to describe the variation of the optical absorption coefficient (a cm-1) versus the photon energy according to the following relations (4-7), where $\mathrm{C}_{0}$, and $\mathrm{R}$ are the absorption strength and excitonic binding energy, respectively. While $\Gamma_{1}$, and $\Gamma_{\mathrm{c}}$ are the linewidth of $\mathrm{m}=1$ state and the linewidth of the continuum state, respectively.

$$
\begin{aligned}
& \alpha(E)=\frac{C_{0} R^{1 / 2}}{E}\left\{\sum_{m=1}^{\infty} \frac{2 R}{m^{3}} \frac{\Gamma_{m}}{\left(E-E_{m}\right)^{2}+\Gamma_{m}^{2}}+\frac{1}{2}\left[\frac{\pi}{2}+\arctan \left[\frac{E-E_{\text {direct }}}{\Gamma_{c}}\right]\right]-\sum_{m=1}^{\infty} \frac{2 R}{m^{3}} \frac{\Gamma_{c}}{\left(E-E_{m}\right)^{2}+\Gamma_{c}^{2}}+\right. \\
& \left.\frac{\pi}{2} \frac{\sinh \left(2 u^{+}\right)}{\cosh \left(2 u^{+}\right)-\cos \left(2 u^{-}\right)}\right\} \\
& u^{ \pm}=\pi\left(\frac{R}{2}\right)^{1 / 2}\left[\frac{\left[\left(E-E_{\text {direct }}\right)^{2}+\Gamma_{c}^{2}\right]^{1 / 2} \pm\left(E-E_{\text {direct }}\right)}{\left(E-E_{\text {direct }}\right)^{2}+\Gamma_{c}^{2}}\right]^{1 / 2} \\
& E_{m}=E_{\text {direct }}-\frac{R}{m^{2}} \\
& \Gamma_{m}=\Gamma_{c}-\frac{\Gamma_{c}-\Gamma_{1}}{m^{2}}, \mathrm{~m}=1,2,3, \ldots .
\end{aligned}
$$

Figures 5(a-d) depict the variation of both measured and simulated absorption coefficient $\alpha(\lambda)$, in $\mathrm{cm}^{-1}$, with the wavelength of the incident photons, for all samples. As shown in those figures 5(ad), there is a good match between the measured and simulated values using the parameters recorded 
in the table (1). The fitting process resulted in the exact value of the optical band edge $E_{m}$, which was consequently used to obtain the corresponding values of $\mathrm{n}, \mathrm{M}, \mathrm{n}_{2}, \chi^{(1)}$, and $\chi^{(3)}$ according to the following relations (8-11) [36-38];

$$
\begin{aligned}
& n=\sqrt{\frac{3.44^{2}}{E_{g}^{0.5}}+3.44^{1 / 2},} \\
& \chi^{(1)}=\frac{n^{2}-1}{4 \pi} \\
& \chi^{(3)}=\left(\chi^{(1)}\right)^{4}\left(1.7 \times 10^{-10}\right)(\text { esu }), \\
& n_{2}=\frac{12 \pi}{n} \chi^{(1)},
\end{aligned}
$$

Table (1) shows that the value of the linear refractive index increased slightly from 2.81 for the graphene-free sample to 2.84 for the graphene-rich sample, which may be assigned to the density increase, and the relative decrease in the number of nonbridging oxygen atoms, as well as the optical edge decrease. As seen in the table (1), the increase in the content of graphene caused both the linear and nonlinear optical susceptibilities to vary from 0.550 to 0.65 , and from $\left(1.56 \times 10^{-11}\right)$ to $\left(1.73 \times 10^{-11}\right)$ esu, respectively. Which is a large variation when compared with that of other materials [38-41] such as the Pure $\mathrm{ZnO}\left(0.117,0.313 \times 10^{-13} \mathrm{esu}\right)$, Co-ZnO (0.13-0.2, 0.489-2.72 $\left.\mathrm{x} 10^{-13} \mathrm{esu}\right)$, and $\mathrm{Sn}-\mathrm{ZnO}\left(1-0.85,0.5-9 \times 10^{-11} \mathrm{esu}\right)$. The same thing was observed for the nonlinear refractive index, which varied from 2.086 to $2.288 \times 10^{-10} \mathrm{esu}$. Accordingly, it can be concluded that the graphene additives act to improve the nonlinear properties of the pure sodium borate glass to be suitable for one of the large nonlinear applications.

\section{Optical absorption \& Glass homogeneity confirmation;}

The optical absorption process is impacted by the internal structure of the absorber material as shown in relation (2), where the absorption coefficient (a) which is an optical property is dependent on the absorber thickness $t$ which is a structure property. The optical absorption depends on the transition of the negative charge carriers between the extended and localized states, as well as the internal asymmetry charge distributions which depend on the structural defects throughout the absorber solid. Such absorption mechanism is known as Urbach's absorption and is described by relation (12) [], where $\mathrm{E}_{\mathrm{U}}$ is known as Urbach's energy. $\mathrm{E}_{\mathrm{U}}$ is equal to the reciprocal of the slope of the straight section of the curve resulted from the plot of $\operatorname{Ln}(\alpha)$ versus $\mathrm{E}$, as shown in figure 
(6). As shown in table (1), the Urbach's energy values varied from $0.621 \mathrm{eV}$ for the graphene-free sample to $0.617 \mathrm{eV}$ for the graphene-rich sample indicates a slight increase in the crystallinity degree. This is what was confirmed by the calculated metallization factor, relation 13) [39-40], which varied from 0.697 for the graphene-free sample to 0.702 for the graphene-rich sample.

$$
\begin{aligned}
& \ln \frac{\alpha}{\alpha_{o}}=\frac{E}{E_{U}} \\
& M=\frac{n^{2}-1}{n^{2}+2}
\end{aligned}
$$

\section{Conclusion:}

Pure graphene has been added to the pure sodium borate glass by different concentrations 1,2 , and $3 \mathrm{~g}$ of the pure graphene per one mole of $\left(\mathrm{Na}_{2} \mathrm{~B}_{4} \mathrm{O}_{7} \cdot 10 \mathrm{H}_{2} \mathrm{O}\right]$. All batches have been melted at 1000 $\pm 20^{\circ} \mathrm{C}$ for two hours then they were poured at room temperature. XRD and FTIR indicated the amorphous natures of the prepared samples, with an increase in $\mathrm{BO}_{4}$ concentration with respect to $\mathrm{BO}_{3}$. Both the bulk density and the hardness increased as the graphene content increased, while the optical absorbance increased. Also, the direct bandgap and indirect bandgap increased, while Urbach's energy decreased. Also, the values of optoelectronic parameters for the present samples are larger than that of the pure $\mathrm{ZnO}$, and $\mathrm{CO}-\mathrm{ZnO}$ which nominates them for the nonlinear optical applications.

\section{Article basic information:}

$>$ Authors confirm that there is no Conflict of Interest or Competing Interests about this work with anybody

$>$ All authors confirm that this work is their original work and they agree to submit it to journal of optical materials

$>$ All original measurements and data analysis of this work will be available when required

$>$ Hosam M. Gomaa \& H. A. Saudi Contributions: Suggested the research idea, Performed All calculations, measurements, and data analysis, wrote the whole mean script

$>$ H. Y. Zahran \& I. S. Yahia Contributions: Reviewing processes

$>$ Acknowledgment

The authors express their appreciation to the Deanship of Scientific Research at King Khalid University for funding this work through a research groups program under grant number R.G.P2/110/41. 


\section{$\underline{\text { References }}$}

1. R. Siburian et al., " New Route to Synthesize of Graphene Nano Sheets", J. oriental journal of chemistry, issn: 0970-020 X, 2018, Vol. 34, No.(1): Pg. 182-187, http://dx.doi.org/10.13005/ojc/340120

2. Rikson S. et al, "Effect of N-Doped Graphene for Properties of Pt/N-Doped Graphene Catalyst", J.ChemistrySelect, 2017, 2, 1188- 1195, https://doi.org/10.1002/slct.201601561

3. Florian B. et al., "Structural defects in graphene", J. ACS Nano. 2011 Jan 25;5(1):26-41, Epub 2010 Nov 23. PMID: 21090760, DOI: 10.1021/nn102598m

4. Tokio Katoh et al., " Growth of N-doped graphene from nitrogen-containing aromatic compounds: the effect of precursors on the doped site", J. RSC Adv., 2016, 6, 13392-13398, DOI: 10.1039/C5RA22664C

5. Wang, H.etal., "Review on Recent Progress in Nitrogen-Doped Graphene: Synthesis, Characterization, and Its Potential Applications", J. Acs Catalysis, 2012, 2, 781-794, https://doi.org/10.1021/cs200652y

6. G.Imamura et al., " effect of UV light-induced nitrogen doping on the field-effect transistor characteristics of graphene", J. RSC Adv., 2015, 5, 70522-70526, https://doi.org/10.1039/C5RA12002K

7. Hosam M. Gomaa, et al., " Influence of the gradual increase of $\mathrm{TiO}_{2}$-impurities on the structural and optical properties of some calcium sodium borate glasses", J. Optik - International Journal for Light and Electron Optics 244 (2021) 167543, https://doi.org/10.1016/j.ijleo.2021.167543

8. Hosam M. Gomaa, et al., "Optical and structural studies of some zinc calcium borate glasses for optoelectronic device applications", J. Mater Sci: Mater Electron (2021) 32:9392-9399, https://doi.org/10.1007/s10854-021-05602-5

9. Hosam M. Gomaa et al., " Effect of $\mathrm{Ag}_{2} \mathrm{O}$ addition on structural and optical characteristics of $\mathrm{B}_{2} \mathrm{O}_{3}-\mathrm{Bi}_{2} \mathrm{O}_{3}-$ $\mathrm{Na}_{2} \mathrm{O}-\mathrm{Nb}_{2} \mathrm{O}_{5}$ oxide glass", J. Optik - International Journal for Light and Electron Optics 247 (2021) 167857, https://doi.org/10.1016/j.ijleo.2021.167857

10. Hossam M. Gomaa et al., " The influence of both $\mathrm{Zn}^{2+}$ and $\mathrm{Ca}^{2+}$ on linear and nonlinear optical parameters of some bismuth borate-based glasses", J. Applied Physics A, (2020) 126:391, https://doi.org/10.1007/s00339-020-03582-7

11. M. Y. Hassaan et al., "Optical Properties of Bismuth Borate Glasses Doped with Zinc and Calcium Oxides",J. Materials and Applications 2020;9(1):46-54, https://doi.org/10.32732/jma.2020.9.1.46

12. Hossam M. Gomaa, "Influence of $\mathrm{Bi}_{2} \mathrm{O}_{3}$ on the physical and electrical properties of some Boro-Iron glasses", J. Journal of Non-Crystalline Solids 481 (2018) 51-58, http://dx.doi.org/10.1016/j.jnoncrysol.2017.10.012

13. M.K. El-Mansy et al. " Effect of exchange of $\mathrm{Bi}^{+3} \mathrm{byNb}^{+5}$ on the structural and optical properties of some $(\mathrm{BBiNb})_{2} \mathrm{O}_{7} \mathrm{CaO}$ oxide glasses", J. Non-Crystalline Solids, Volume 485, 1 April 2018, Pages 42-46, https://doi.org/10.1016/j.jnoncrysol.2018.01.036

14. H. M. Gomaa et al., "Correlate the structural changes to gamma radiation shielding performance evaluation for some calcium bismuth-borate glasses containing $\mathrm{Nb}_{2} \mathrm{O}_{5}$ ", J. Physica B: Condensed Matter, Volume 567, 15 August 2019, Pages 109-112, https://doi.org/10.1016/j.physb.2018.11.011 
15. Hossam Mohamed Gomaa \& N. Hendawy, " Effect of $\mathrm{Ag}^{+}$Ions on the Properties of Some Calcium Niobium Bismuth Borate Glasses", J. IOSR Journal of Applied Physics (IOSR-JAP), e-ISSN: 2278-4861.Volume 10, Issue 3 Ver. II (May. - June. 2018), PP 01-04, DOI: 10.9790/4861-1003020104

16. Moecher, David, 2004, Characterization and Identification of Mineral Unknowns: A Mineralogy Term Project, Jour. Geoscience Education, v 52 \#1, p. 5-9.

17. Hluchy, M.M., 1999, The Value of Teaching X-ray Techniques and Clay Mineralogy to ndergraduates, Jour. Geoscience Education, v. 47, p. 236-240

18. Yin Cheng, et al., "Structure and crystallization kinetics of $\mathrm{PbO} \mathrm{B}_{2} \mathrm{O}_{3}$ glasses", J. Ceram. Int. 33 (7) (2007) 1341-1347, https://doi.org/10.1016/j.ceramint.2006.04.025

19. Dale Stentz, et al., "Analysis of the structure of lead borosilicate glasses using laser ionization time of flight mass spectroscopy", J. Non-Cryst. Solids 293 (2001) 416-421, https://doi.org/10.1016/S00223093(01)00837-7

20. A. Aronne, et al., "FTIR and DTA study of structural transformations and crystallization in $\mathrm{BaO}_{2} \mathrm{O}_{3} \mathrm{TiO}_{2}$ glasses", Phys. Chem. Glasses 40 (2) (1999) 63-68

21. Iglesias et al., "On the Tannic Acid Interaction with Metallic Iron”, J. Hyperfine Interact. 2001, 134, 109, https://doi.org/10.1023/A:1013838600599

22. A. H. Verhoef and H.W. den Hartog, "Infrared spectroscopy of network and cation dynamics in binary and mixed alkali borate glasses," J. Non-Crystalline Solids, vol.182, no.3, pp.221-234, 1995

23. KH. S. Shaaban et al., "Physical and Structural Properties of Lithium Borate Glasses Containing MoO3", J. DOI 10.1007/s12633-016-9519-4.1

24. I. Kashif and A Ratep, "Role of copper metal or oxide on physical properties of lithium borate glass", Journal of Molecular Structure 1102 (2015) 1-5, DOI:10.1016/J.MOLSTRUC.2015.07.070

25. Yasser B. Saddeek et al., "Optical and structural evaluation of bismuth alumina-borate glasses doped with different amounts of $\left(\mathrm{Y}_{2} \mathrm{O}_{3}\right)$ ", J. Non-Crystalline Solids $454 \quad$ (2016) 13-18., https://doi.org/10.1016/j.jnoncrysol.2016.10.023

26. Reham M. M. Morsi et al., "Effect of alkaline earth metal oxides on the dielectric, structural and physicochemical properties of lithium-zinc-lead-borates”, J. Mater Sci: Mater Electron (2016) 27:4147-4156, https://doi.org/10.1007/s10854-016-4276-0

27. S. Cetinkaya Colak, "Role of titanium ions on the optical and thermal properties of zinc borate glass doped with $\mathrm{TiO}_{2}$ ”, J. Phys. Chem. Glasses: Eur. J. Glass Sci. Technol. B, February 2017, 58 (1), 41-48, DOI: 10.13036/17533562.57.2.067

28. Hosam M. Gomaa et al., "Impact of graphite impurities on the structure and optical properties of the sodium borate oxide glass", J. Mater Sci: Mater Electron (2021). https://doi.org/10.1007/s10854-021-07130-8

29. AL-Gahouari et al., "Controlling reduction degree of graphene oxide-based electrode for improving the sensing performance toward heavy metal ions", J. Appl. Phys. A 127, 170 (2021). https://doi.org/10.1007/s00339-020-04199-6 
30. M. Ghamari and B. Mirhad, "Composition dependence of spectroscopic properties and transparency of $\mathrm{SiO}_{2-}$ $\mathrm{TiO}_{2}-\mathrm{Na}_{2} \mathrm{O}$ glass in 200-1100 nm”, J. Iranian Journal of Materials Science \& Engineering Vol. 9, Number 2, June 2012, DOI: 10.4191/kcers.2017.54.2.01

31. Hosam M Gomaa et al., "Optical and structural studies of some zinc calcium borate glasses for optoelectronic device applications”, J. Mater Sci: Mater Electron, (2021) 32:9392-9399, J Mater Sci: Mater Electron(2021) 32:9392-9399, https://doi.org/10.1007/s10854-021-05602-5

32. Mahmoud Nasr, et al., "Novel thermochromic (TC) and electrochromic (EC) characteristics of the $\mathrm{V}_{4} \mathrm{O}_{7}$ liquid crystal for LCDs and versatile optoelectronic applications", J. Molecular Liquids 330 (2021) 115620, https://doi.org/10.1016/j.molliq.2021.115620

33. Saeid M. Elkatlawy, et al., "Structural properties, linear, and non-linear optical parameters of ternary $\mathrm{Se}_{80} \mathrm{Te}_{(20-x)}$ In chalcogenide glass systems”, J. Bol. Soc. Esp. Cerám. Vidr. (2020), https://doi.org/10.1016/j.bsecv.2020.09.007

34. Ahmed S. Hassanien and Ishu Sharma, "Optical properties of quaternary a-Ge ${ }_{15-x} \mathrm{Sb}_{\mathrm{x}} \mathrm{Te}_{35}$ thermally evaporated thin-films: refractive index dispersion and single oscillator parameters", J. Optik- international journal for light and electron Optics 200 (2020) 163415

35. Berwal, N. et al., "Study of vibrational spectroscopy, linear and nonlinear optical properties of boratemodified tellurium-silica-bismuthate glasses", Indian J Phys 94, $1643-1652$ (2020). https://doi.org/10.1007/s12648-019-01604-6

36. M. Ghamari and B. Mirhad, "Composition dependence of spectroscopic properties and transparency of $\mathrm{SiO}_{2-}$ $\mathrm{TiO}_{2}-\mathrm{Na}_{2} \mathrm{O}$ glass in 200-1100 nm”, J. Iranian Journal of Materials Science \& Engineering Vol. 9, Number 2, June 2012, DOI: 10.4191/kcers.2017.54.2.01

37. ahmoud Nasr, et al., "Novel thermochromic (TC) and electrochromic (EC) characteristics of the $\mathrm{V}_{4} \mathrm{O}_{7}$ liquid crystal for LCDs and versatile optoelectronic applications”, J. Molecular Liquids 330 (2021) 115620, https://doi.org/10.1016/j.molliq.2021.115620

38. Kaur, R., Rakesh, R.B., Mhatre, S.G. et al. Thermoluminescence, structural and optical properties of $\mathrm{Ce}^{3+}$ doped borosilicate doped glasses. J Mater Sci: Mater Electron 32, 18381-18396 (2021). https://doi.org/10.1007/s10854-021-06382-8

39. Ganesh et al., "Sn-doped $\mathrm{ZnO}$ nanocrystalline thin films with enhanced linear and nonlinear optical properties for optoelectronic applications", J. Physics and Chemistry of Solids, Volume 100, 2017, Pages 115-125, ISSN 0022-3697, https://doi.org/10.1016/j.jpcs.2016.09.022.

40. D. Joseph Edison et al., " Structural, optical and nonlinear optical studies of AZO thin film prepared by SILAR method for electro-optic applications", J. Physica B: Condensed Matter, Volume 523, 2017, Pages 31-38, ISSN 0921-4526, https://doi.org/10.1016/j.physb.2017.08.021.

41. Albin Antony et al., " Effect of electron beam on structural, linear and nonlinear properties of nanostructured Fluorine doped ZnO thin films”, J. Physica E: Low-dimensional Systems and Nanostructures, Volume 94, 2017, Pages 190-195, ISSN 1386-9477, https://doi.org/10.1016/j.physe.2017.08.015. 
Table (1):

\begin{tabular}{|c|c|c|c|c|}
\hline & $S 1$ & $S 2$ & $S 3$ & $S 4$ \\
\hline$\rho$ & 2.34 & 2.35 & 2.38 & 2.41 \\
\hline$H v$ & 395.02 & 401.73 & 414.92 & 423.26 \\
\hline$E_{U},(e V)$ & 0.621 & 0.618 & 0.617 & 0.617 \\
\hline$E($ direct $),(e V)$ & 3.36 & 3.36 & 3.41 & 3.51 \\
\hline$E($ indirect $),(e V)$ & 2.81 & 2.81 & 3.12 & 3.18 \\
\hline$E_{m}(e V)$ & 3.72 & 3.72 & 3.66 & 3.5 \\
\hline$R,(e V)$ & 0.1 & 0.1 & 0.1 & 0.1 \\
\hline$\Gamma_{1},(e V)$ & 0.140 & 0.140 & 0.145 & 0.16 \\
\hline$\Gamma_{c},(e V)$ & 0.1 & 0.1 & 0.1 & 0.1 \\
\hline$C_{0},\left(e V^{1 / 2} \mathrm{~cm}^{-1}\right)$ & 200 & 200 & 200 & 200 \\
\hline$n$ & 2.81 & 2.81 & 2.82 & 2.84 \\
\hline$M$ & 0.697 & 0.697 & 0.699 & 0.702 \\
\hline$\chi^{(1)}$ & 0.550 & 0.550 & 0.554 & 0.565 \\
\hline$\chi^{(3)}\left(10^{-11}\right),(e s u)$ & 1.56 & 1.56 & 1.60 & 1.73 \\
\hline$n 2\left(10^{-10}\right),(e s u)$ & 2.086 & 2.086 & 2.138 & 2.288 \\
\hline
\end{tabular}




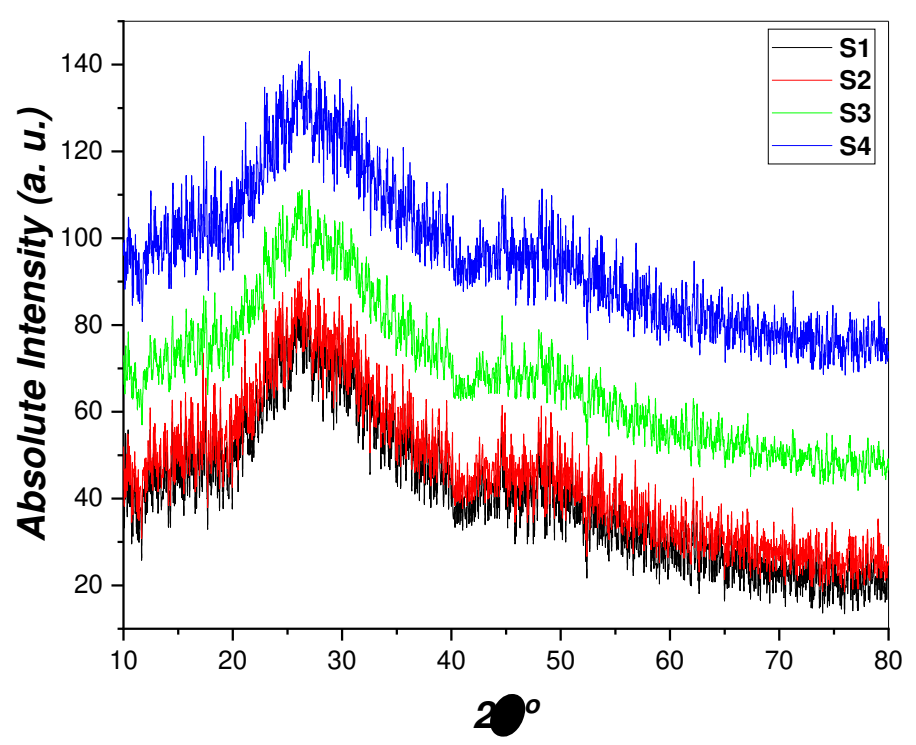

Fig.(1a):

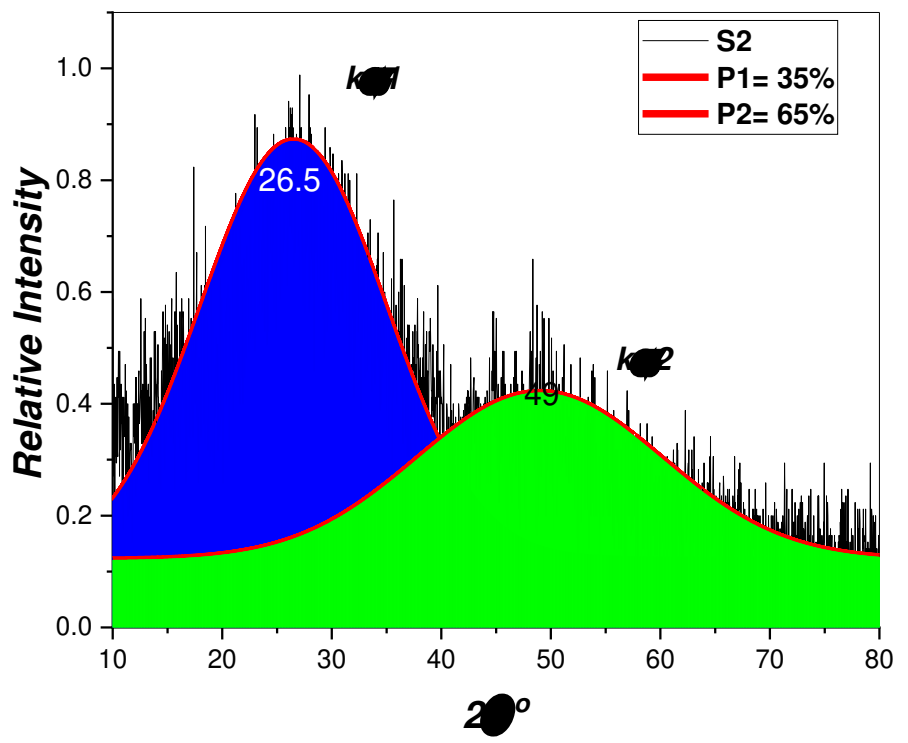

Fig.(1b): Normalized XRD Patterns for S2 


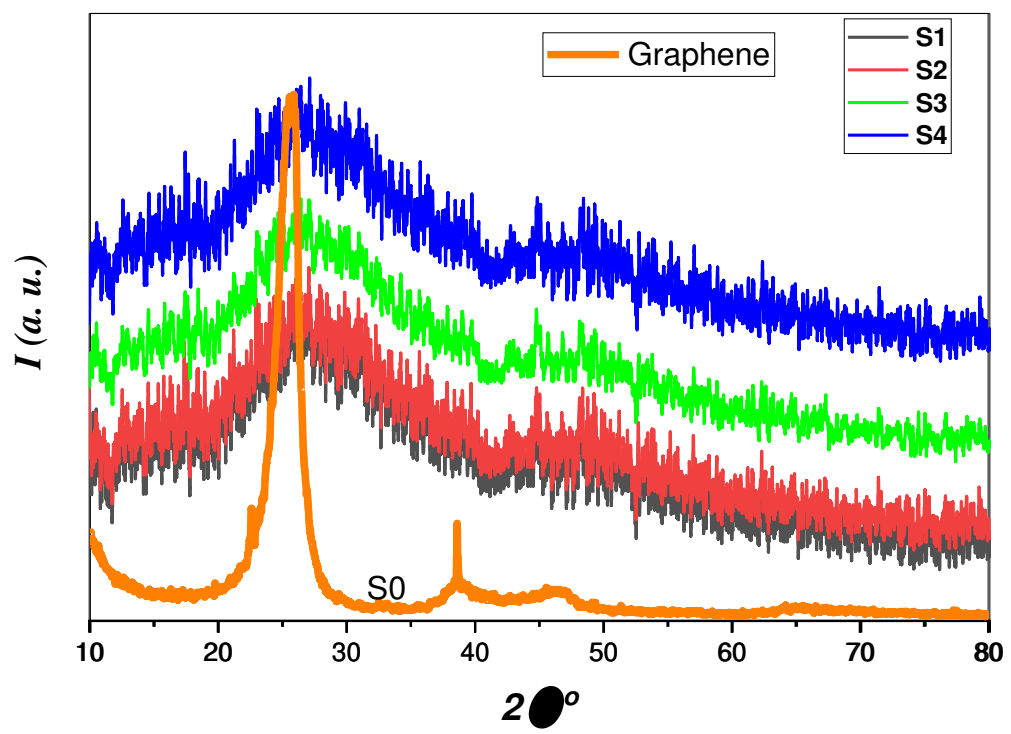

Fig. (1c):

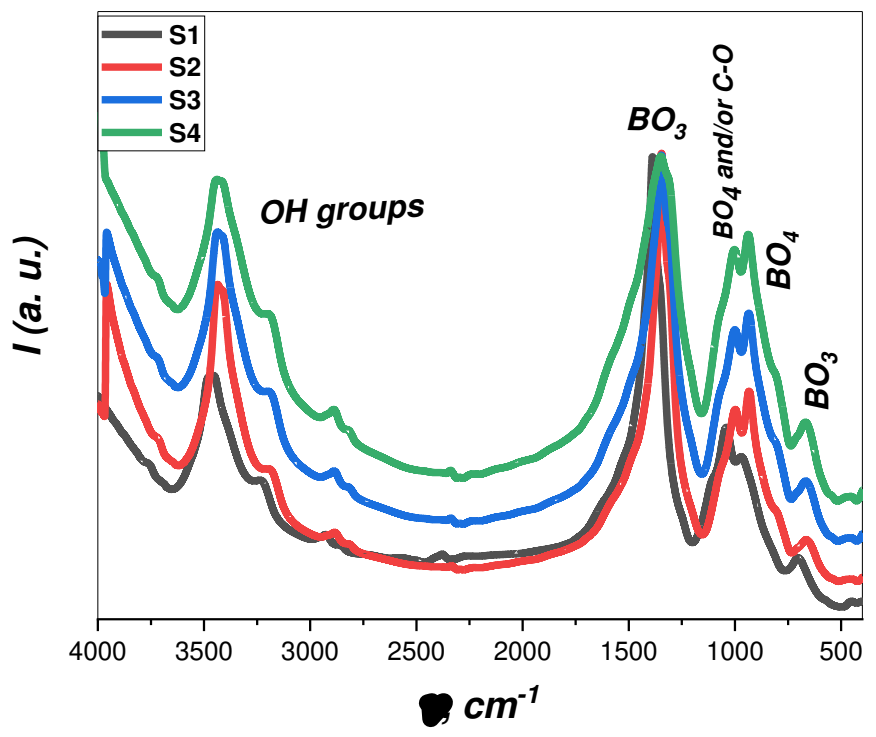

Fig. (2a) 


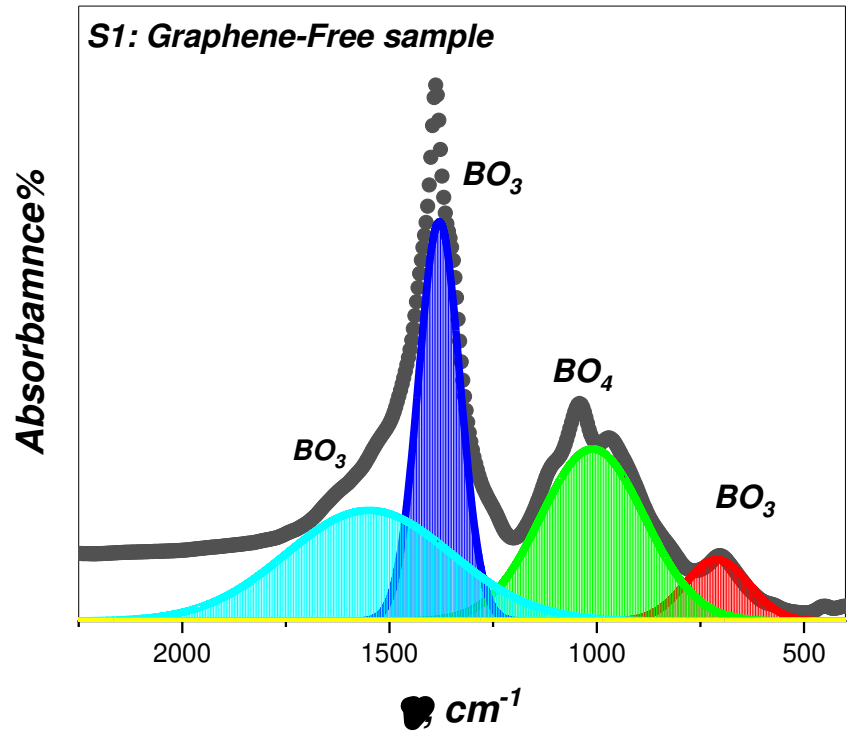

Fig. (2b):

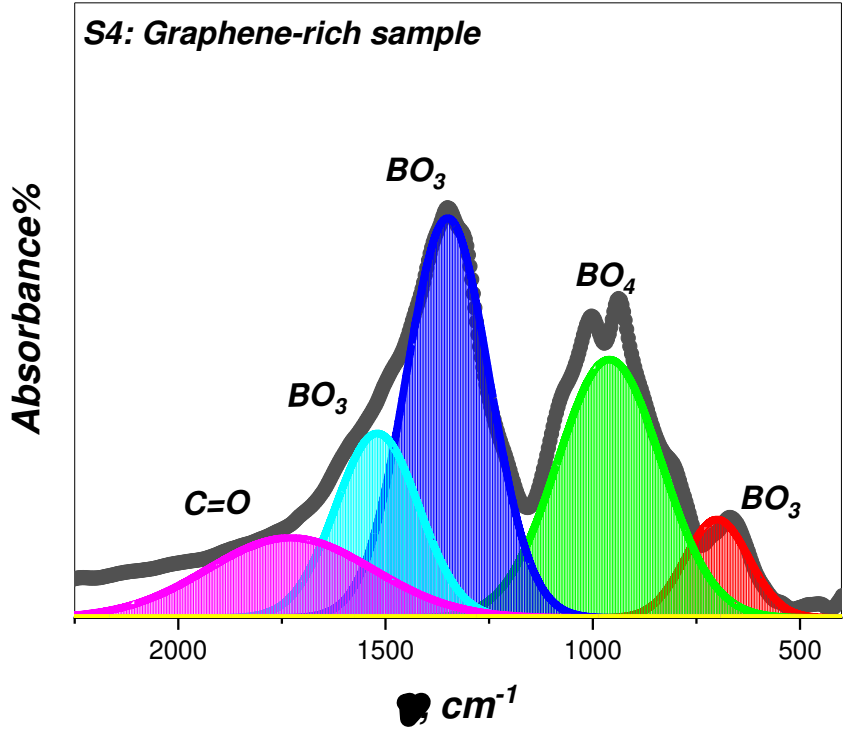

Fig.(2c): 


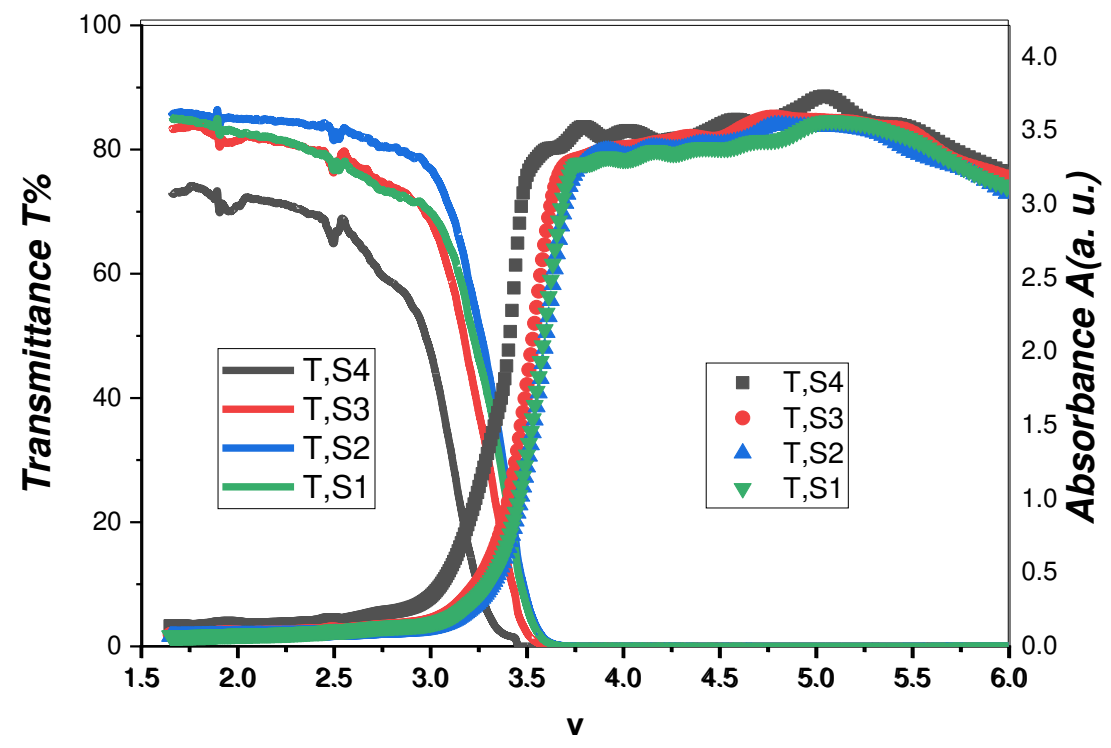

Fig.(3)

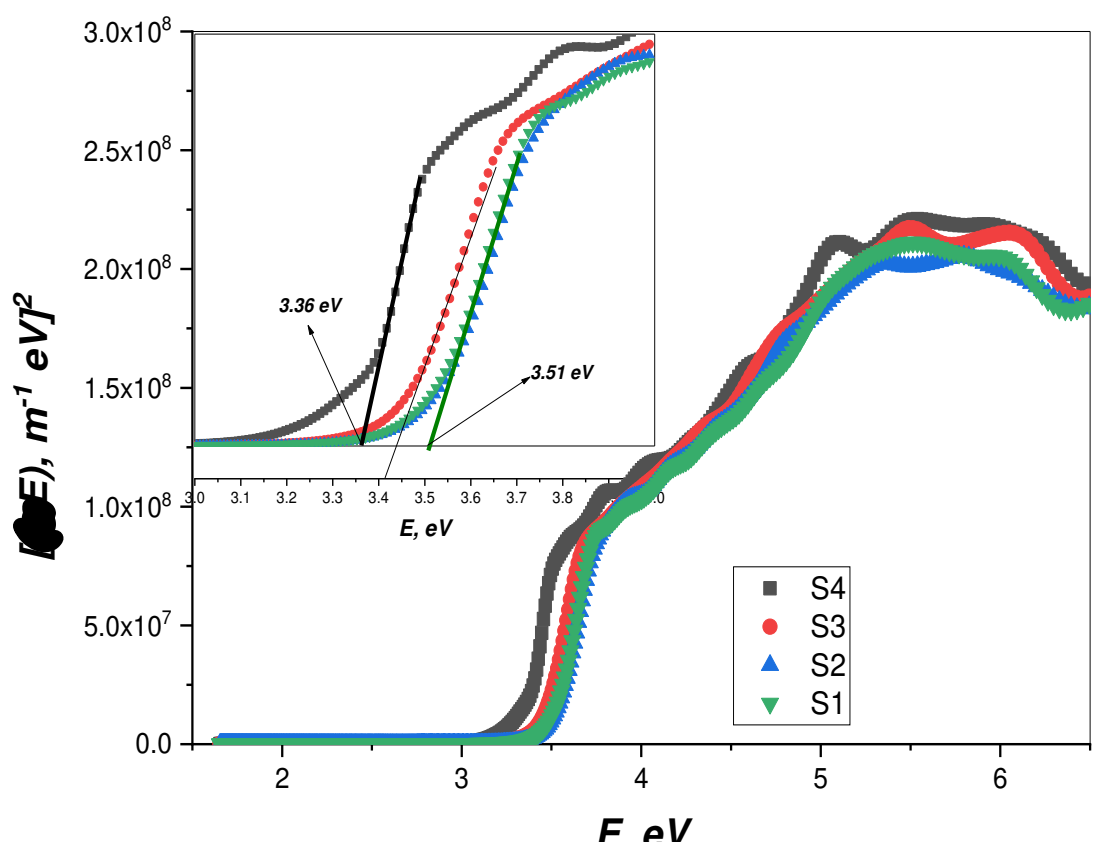

Fig.(4a): 


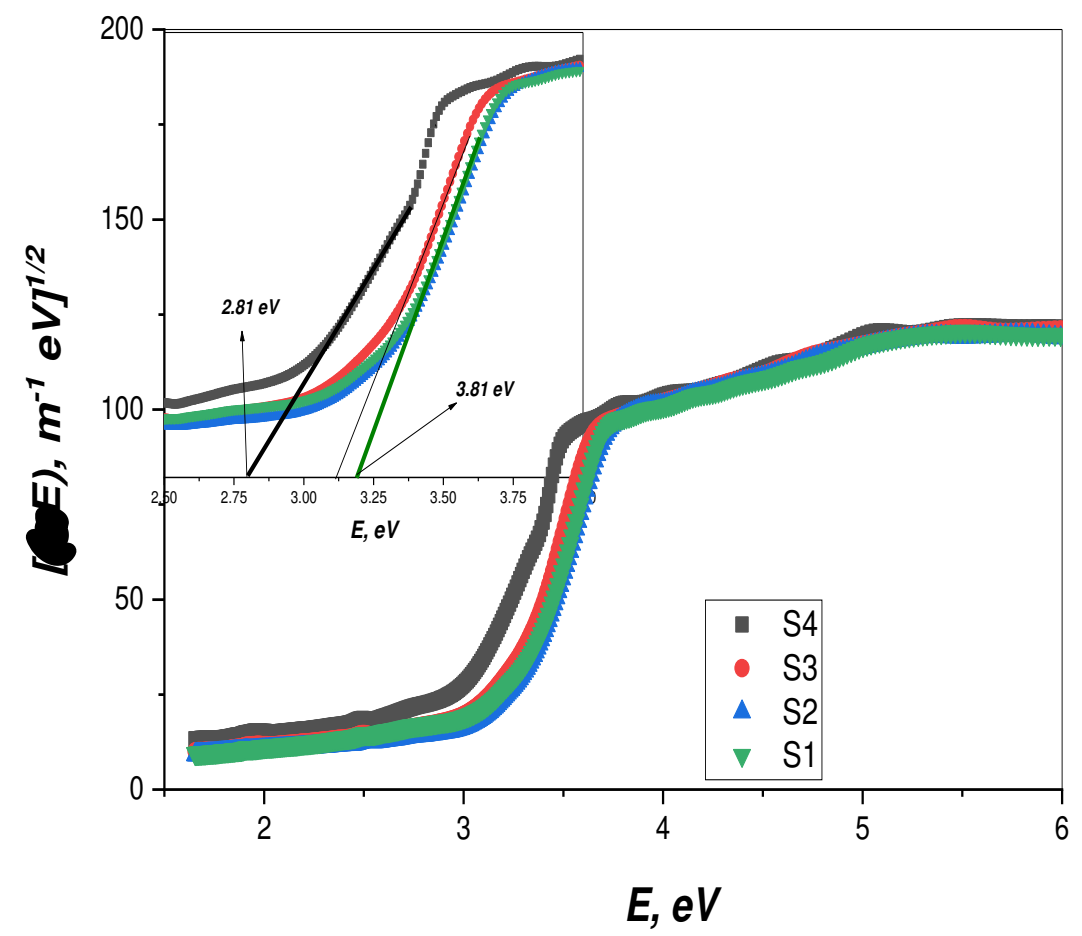

Fig. (4b)

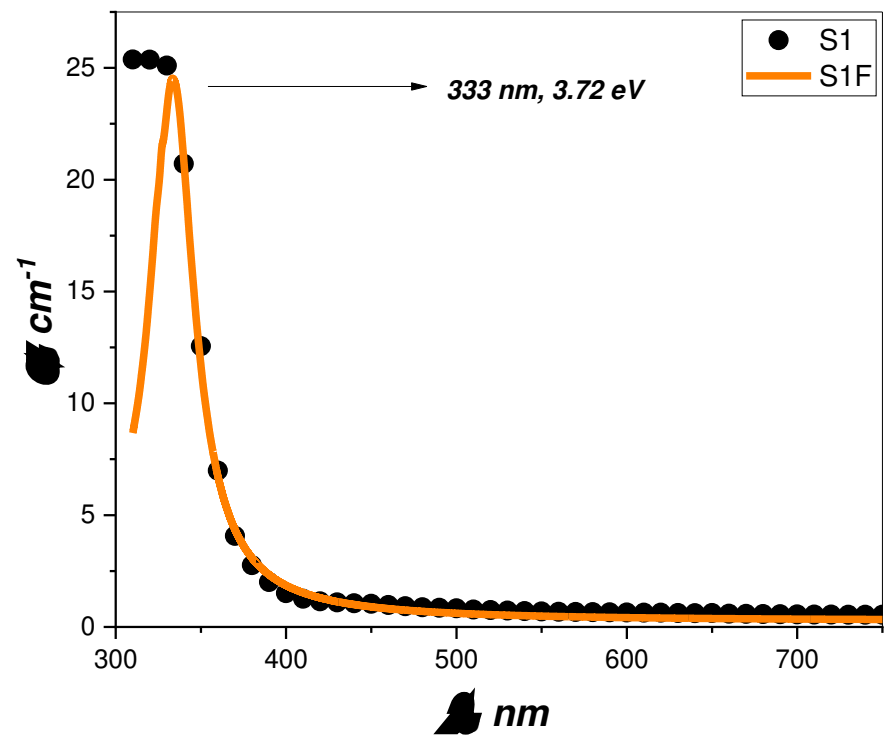

Fig. (5a): 


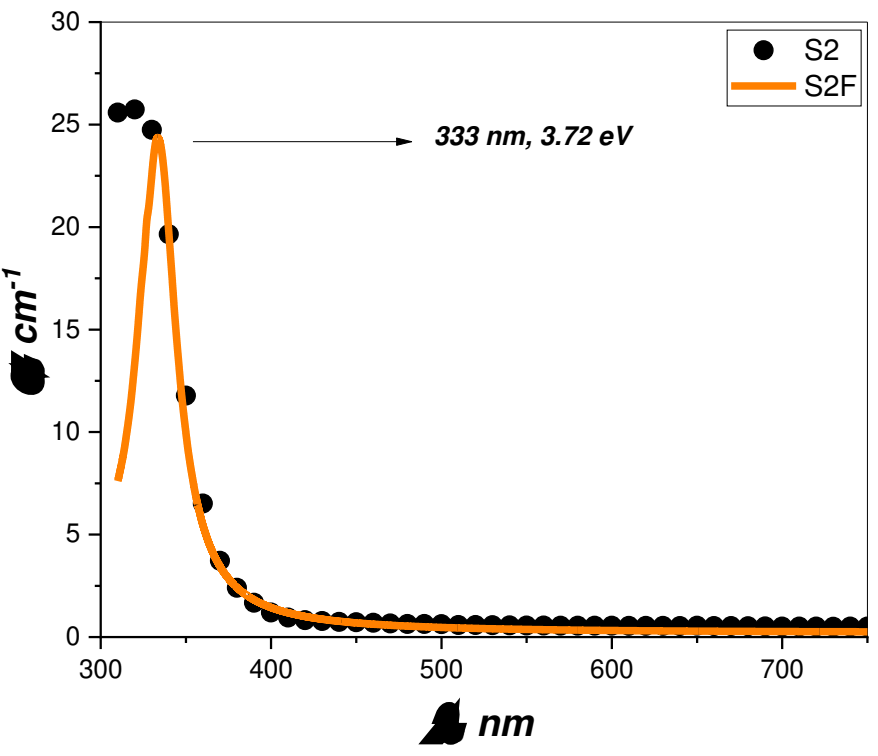

Fig.(5b):

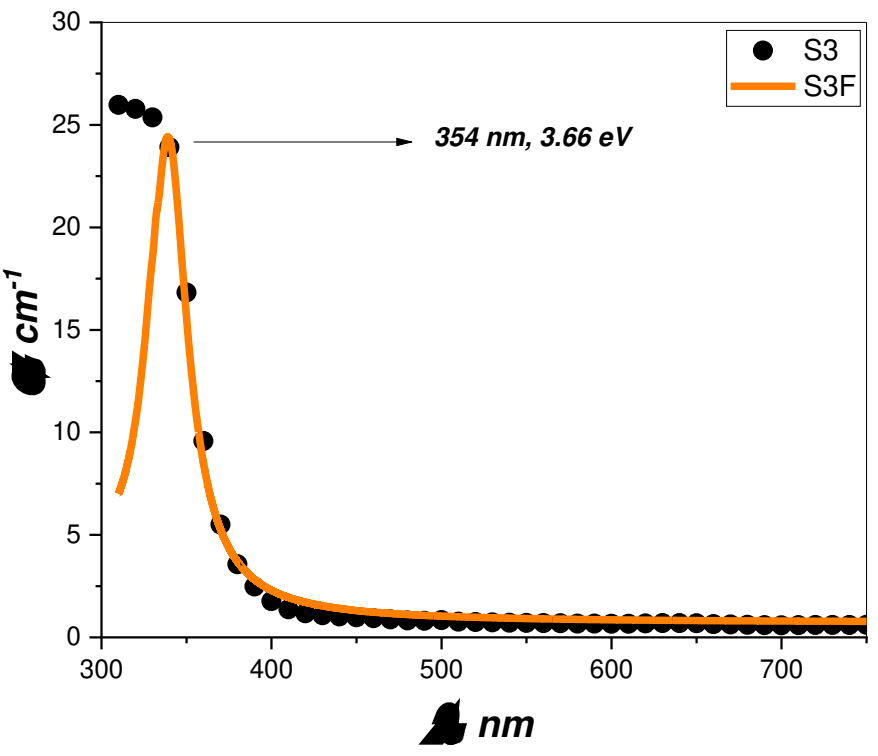

Fig.(5c): 


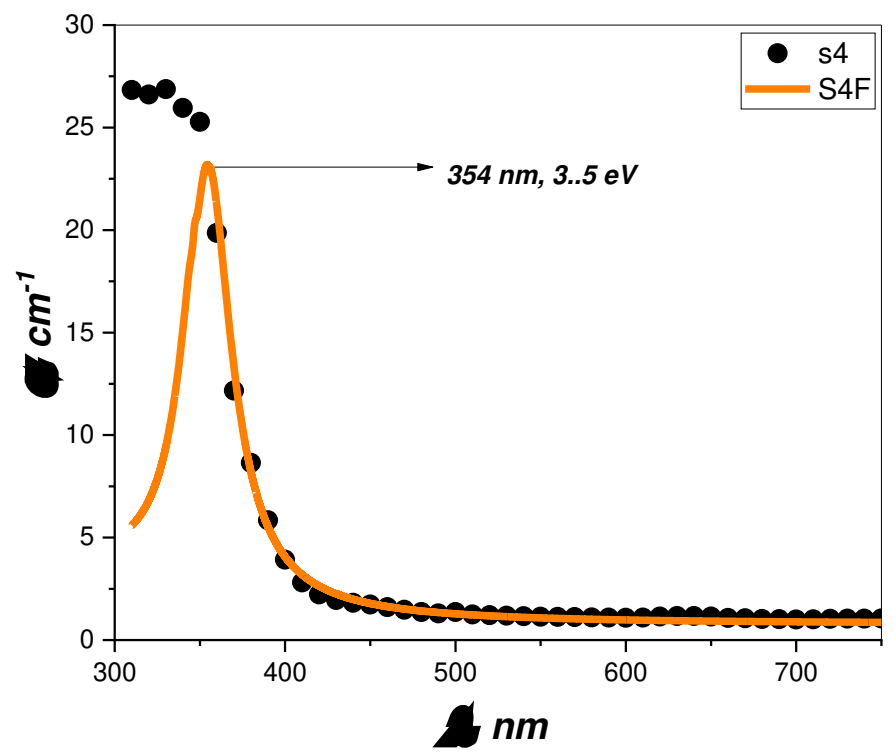

Fig.(5d)
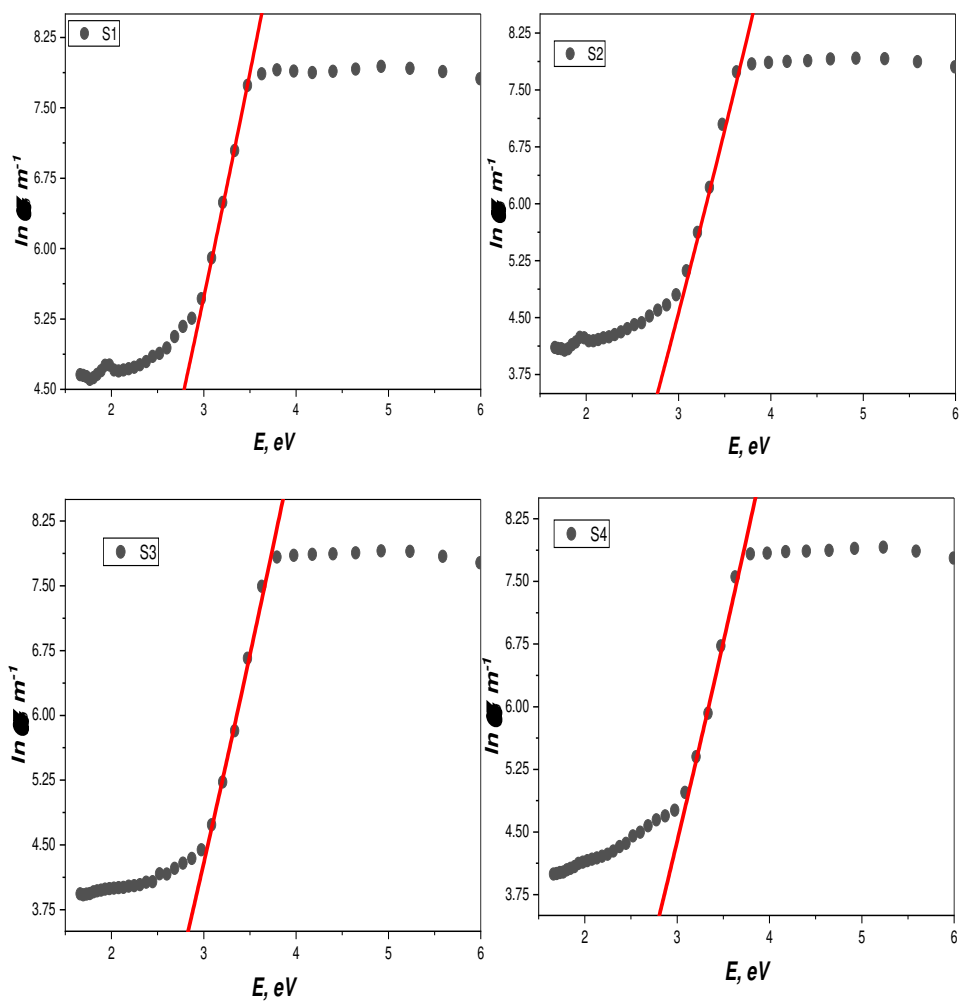

Fig.(6): 